\title{
BINARY VECTOR CONSTRUCTION AND Agrobacterium tumefaciens-MEDIATED TRANSFORMATION OF LYSOZYME GENE IN SEAWEED Kappaphycus alvarezii
}

\author{
TRI HANDAYANI ${ }^{1,2 *}$, ALIMUDDIN ${ }^{1}$, UTUT WIDYASTUTI ${ }^{3}$, EMMA SURYATI ${ }^{4}$ \\ and ANDI PARENRENGI ${ }^{4}$ \\ ${ }^{1}$ Department of Aquaculture, Faculty of Fisheries and Marine Sciences, \\ Bogor Agricultural University, Bogor 16680, Indonesia \\ ${ }^{2}$ Research Center for Oceanography, Indonesian Institute of Science, Jakarta 14430, Indonesia \\ ${ }^{3}$ Research Center for Bioresources and Biotechnology, Bogor Agricultural University and \\ Department of Biology, Faculty of Mathematics and Natural Sciences, \\ Bogor Agricultural University, Bogor 16680, Indonesia \\ ${ }^{4}$ Research Institute for Coastal Aquaculture, Maros, South Sulawesi, Indonesia
}

Received 19 November 2013/Accepted 6 September 2014

\begin{abstract}
Ice-ice disease is the biggest problem in the cultivation of seaweed Kappaphycus alvarezii. The disease is caused by bacterial infection and induced by drastic changes of water quality. Lysozyme has the ability to break down bacterial cell wall. The purpose of this research was to construct of a binary vector pMSH1-Lys carrying chicken Lysozyme (Lys) gene and to introduce pMSH1-Lys on $K$. alvarezii. The binary vector expression was transformed into Agrobacterium tumefaciens LBA4404 by triparental mating. Thallus was inoculated with $A$. tumefaciens carrying pMSH1-Lys and then the transformed thallus was selected by adding 20 $\mathrm{mg} / \mathrm{L}$ hygromycin to the culture medium. Polymerase Chain Reaction (PCR) analysis showed that the construction of the binary plasmid pMSH1-Lys was established. Percentage of pMSH1-Lys transformation on $K$. alvarezii was $23.56 \%$, while the efficiency of regeneration was $11.32 \%$. PCR analysis showed that three of the regenerated thallus contained Lysozyme gene. Thus, transgenic $K$. alvarezii was successfully produced. These findings can be useful for studying the mechanisms of seaweed defense against bacterial infection.
\end{abstract}

Keywords: Agrobacterium tumefaciens, genetic transformation, Kappaphycus alvarezii, Lysozyme

\section{INTRODUCTION}

Kappaphycus alvarezii (Doty) is economically important red tropical seaweed highly demanded for its cell wall polysaccharides, being the most important source of kappa-

$\overline{\text { * Corresponding author : umuamel@gmail.com }}$ 
carrageenan in the world (Bixler 1996). Carrageenan is used in industries including food, textile, cosmetic, pharmaceutical and photography (Yu et al. 2002). Kappacarrageenan is used as stabilizers, thickeners and emulsifiers (Bixler 1996).

Seaweed production can be increased by extensification and improvement of cultivation method. However, ice-ice disease is the biggest problem in seaweed cultivation. Ice-ice infection can spread in broad area of cultivation for a week, and cause thallus damage about $60-80 \%$ within 1-2 months (Sulistijo, Personal communication, 2002). Carrageenan content in the ice-ice infected seaweed decreases (Amiluddin 2007), and this leads to loss for farmers (Yulianto \& Mira 2009).

Bacteria are suspected as causative agents of ice-ice disease, including Psendomonas nigricaciens, P. fluorescens, Vibrio granii, Bacillus cereus and V. agarliquefaciens. Vibrio agarliquefaciens shows the highest pathogenicity (Nasution 2005). Largo (2002) also found Vibrio sp. on ice-ice infected thalli. Furthermore, Aris (2011) reported five bacteria on ice-ice infected $K$. alvarezii thalli, namely Flavobacterium meningosepticum, $V$. alginoliticus, Pseudomonas cepacia, P. diminuta and Plesiomonas shigelloides.

Genetic engineering techniques can be used to make seaweed resistant to bacterial infections. As the first step, Takahashi et al. (2010) had transformed glucuronidase gene into Porphyra yezoensis thallus by particle bombardment. Huddy et al. (2012) had also successfully introduced the LacZ gene into the Gracilaria gracilis thallus by particle bombardment. In plant transgenic production, a foreign gene is generally transferred using Agrobacterium tumefaciens. The method has advantages such as having relatively low cost, small copy number of gene and reproducibility (Hiei et al. 1997). A. tumefaciens contains binary expression vector. The first vector is part of the virulent $A$. tumefaciens, but without helper T-DNA, while the second vector is smaller and contains a T-DNA gene to be inserted (Loeidin 1994).

Lysozyme has been used to generate transgenic fishes that are resistant to bacterial infections, such as zebrafish (Yazawa et al. 2006), shrimp (Litopenaeus vannamer) (Burge et al. 2007) and salmon (Salmo salar L.) (Fletcher et al. 2011). Lysozyme is small ubiquitous antibacterial enzyme that hydrolyzes $\beta$-1, 4-linked glycoside bonds of peptidoglycan, a major cell wall component of gram-positive bacteria (Li et al. 2008). In addition, lysozyme is also able to kill gram-negative bacteria infecting bivalves and shrimp (Burge et al. 2007). Yazawa et al. (2006) established a transgenic zebrafish strain expressing chicken lysozyme gene. In the challenge experiment, $65 \%$ of the F2 transgenic zebrafish survived when infected by Flavobacterium columnare and $60 \%$ fish survived when infected by Edwardsiella tarda, whereas all non-transgenic fish were died. The lysozyme lytic activity of F2 in transgenic salmon was $40 \%$ greater than that in non-transgenic siblings (Fletcher et al. 2011). Chicken lysozyme possessed lytic activities against Micrococcus lysodeikticus, Flavobacterium columnare, Aeromonas bydropbilla and Vibrio anguillarum (Yazawa et al. 2006). Thus, chicken lysozyme is an important component of immune defense against diverse bacterial infections that can be exploited to increase seaweed resistance against pathogens. The aims of this study were to construct a binary plasmid carrying chicken lysozyme gene and to transfer it into $K$. alvarezii thallus by using $A$. tumefaciens . 


\section{MATERIALS AND METHODS}

\section{Kappaphycus alvarezii and Sterilization}

Kappaphycus alvarezii thalli with green color were obtained from Lampung, Sumatera Island, Indonesia. Thalli were maintained in fiber tanks with a flow-through water system, aerated and under a 12/12 hours (light/dark) photoperiod at room temperature. Kappaphycus alvarezii thalli were cut about $3 \mathrm{~cm}$ in length and then sterilized by $1 \%$ iodine solution and detergent. The thalli were maintained in Prevasoli (PES) medium liquid until they were ready to be transformed.

\section{Construction of Lysozyme-expressing Plasmid}

Binary vector pMSH1 (Nara Institute of Science and Technology, Japan; Fig. 1) was used for the construction of Lysozyme (Lys) expression vector. Lys gene was amplified from pJfKer-Lys (Yazawa et al. 2005; Fig. 2) using specific PCR primers LysF: 5'-GCA CTA GTG GCA ACA TGA GGT CT'T TGC-3' and Lys-R: 5'-T'TG CGG CCG CTC CTC ACA GCC GGC AGC-3'. PCR was performed with 2 minutes initial denaturation at $94^{\circ} \mathrm{C}$ and then 35 cycles were run at: 30 seconds denaturation at $94^{\circ} \mathrm{C}$, 30 seconds annealing at $64^{\circ} \mathrm{C}\left(\right.$ at $59^{\circ} \mathrm{C}$ for Nos terminator) and 1 minute of extension at $72^{\circ} \mathrm{C}$. The amplified products were electrophoresed on a $2 \%$ agarose gel with $1 \mathrm{x}$ TAE buffer. The DNA of pMSH1 and PCR product of Lys gen were cut by restriction enzymes NotI and SpeI. Lys gene was ligated with NotI and SpeI-digested pMSH1. This recombinant binary vector was designated as pMSH1-Lys. Plasmid pMSH1-Lys was then transformed into Eschericbia coli $\mathrm{DH} 5 \alpha$ by heat shock (Suharsono et al. 2002). Transformant E.coli DH5 $\alpha$ was identified by PCR method using Lys specific primer, and restricted using NotI and SpeI enzymes.

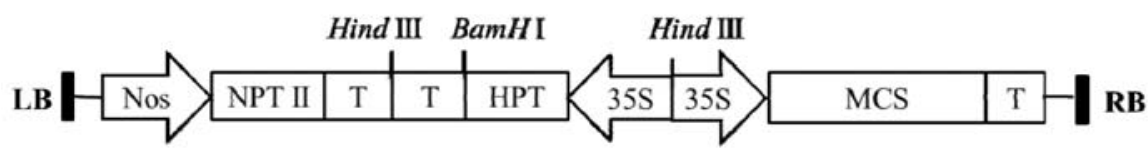

Figure 1. Map of the T-DNA plasmid pMSH1 (NAIST, Japan). NPT II: neomycin phosphotransferase II, a selection marker gene. HPT: hygromycin phosphotransferase, a selection marker gene. MCS: multi cloning site, regions of target genes that is controlled by the cauliflower mosaic virus $35 \mathrm{~S}$ promoter (CaMV 35S) and terminator (T) nopaline synthase (Nos), containing XbaI, XboI, SacI, SmaI, KpnI, SpeI, NotI, BamHI

\section{Transformation of pMSH1-Lys into Agrobacterium tumefaciens}

Plasmid pMSH1-Lys was transformed into $A$. tumefaciens by tri-parental mating (Liberty et al. 2008). Tri-parental mating was carried out using E. coli DH5 $\alpha$ carrying pMSH1-Lys $\left(\mathrm{Kan}^{\mathrm{R}}, \mathrm{Hyg}^{\mathrm{R}}\right)$ as the donor strain, E. coli DH1 carrying pRK2013 $\left(\mathrm{Kan}^{\mathrm{R}}\right)$ as 


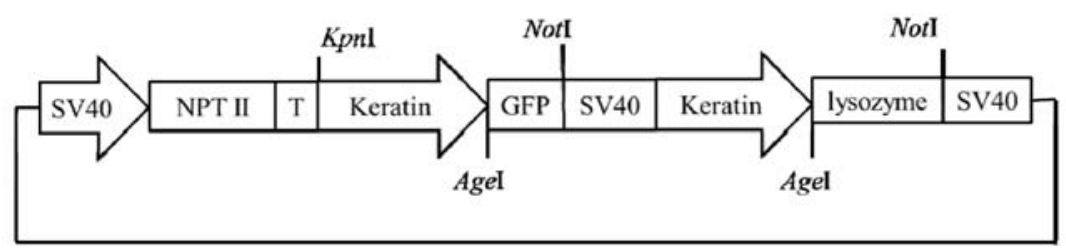

Figure 2. Map of pJfKer-Lys (Yazawa et al. 2005). Chicken lysozyme gene is controlled by the promoter of keratin (keratin) Japanese flounder (Paralichthys olivaceus). SV40: simian virus 40 terminator. NPT II: neomycin phosphotransferase, GFP: green flourescense protein

the helper strain, and $A$. tumefaciens LBA4404 $\left(\right.$ Strep $\left.^{\mathrm{R}}\right)$ as the recipient. $A$. tumefaciens was grown at room temperature on LB medium with $50 \mu \mathrm{g} / \mathrm{L}$ streptomycin. E. coli DH5 $\alpha$ containing pMSH1-Lys was grown at $37^{\circ} \mathrm{C}$ on LB medium with $50 \mathrm{mg} / \mathrm{L}$ kanamycin and $50 \mathrm{mg} / \mathrm{L}$ hygromycin. E. coli DH1 bearing helper plasmid pRK2013 was grown at $37^{\circ} \mathrm{C}$ on LB medium with $50 \mu \mathrm{g} / \mathrm{L}$ kanamycin.

About $20 \mu \mathrm{L}$ bacteria consisted of E. coli DH5 $\alpha$, E. coli DH1 and $A$. tumefaciens were cultured together (conjugation="konjugasi") for 36 hours at room temperature. $A$. tumefaciens conjugated product was identified by antibiotic selection (kanamycin 50 $\mathrm{mg} / \mathrm{L}$, hygromycin $50 \mathrm{mg} / \mathrm{L}$ and streptomycin $50 \mathrm{mg} / \mathrm{L}$ ), and PCR method using specific primers: for Lys gene was Lys-F: 5'-GCA CTA GTG GCA ACA TGA GGT CT'T TGC-3' and Lys-R: 5'-T'TG CGG CCG CTC CTC ACA GCC GGC AGC-3'; for 35S CaMV promoter was 35SCaMV-F: 35S-F: 5'-ATG GCT GGA GTA TTA GCT GGG-3' and Lys-R: 5'-T'TG CGG CCG CTC CTC ACA GCC GGC AGC -3; for Nos terminator was Lys-F: 5'-GCA CTA GTG GCA ACA TGA GGT CT'T TGC-3' and Nos-R: 5'-CTC ATA AAT AAC GTC ATG CAT TAC A-3'. PCR was performed with 2 minutes initial denaturation at $94{ }^{\circ} \mathrm{C}$ and then 35 cycles were run at: 30 seconds denaturation at $94{ }^{\circ} \mathrm{C}, 30$ seconds annealing at $64{ }^{\circ} \mathrm{C}$ (at $59{ }^{\circ} \mathrm{C}$ for Nos terminator) and 1 minute extension at $72^{\circ} \mathrm{C}$. The amplified PCR products were electrophoresed on $2 \%$ agarose gel with $1 \mathrm{x}$ TAE buffer.

\section{Preparation of Agrobacterium Suspension for Co-cultivation}

A single colony of $A$. tumefaciens containing pMSH1-Lys was incubated in $5 \mathrm{~mL}$ of LB medium and grown for 36 hours on a $200 \mathrm{rpm}$ shaker at room temperature. The bacterial culture was refreshed in $10 \mathrm{~mL}$ of LB medium and grown for 18 hours on a $200 \mathrm{rpm}$ shaker at room temperature to an OD600 of 0.5-1.0. The bacterial culture was centrifuged at 5,000 rpm and the pellet was resuspended in $25 \mathrm{~mL}$ of liquid suspension medium containing PES and $100 \mu \mathrm{M}$ acetosyringone. The suspension was used for thalli transfection. 


\section{Production of Transgenic Kappaphycus alvarezii}

Transgenic K. alvarezii were produced as previously reported (Cheney et al. 2001). Seaweed thalli (1-2 cm in length) were wounded by sterile syringe and infected by $A$. tumefaciens carrying pMSH1-Lys for 30 minutes in suspension medium containing PES and $100 \mu \mathrm{M}$ acetosyringone. The infected thalli were transferred to co-cultivation medium (PES medium containing $100 \mu \mathrm{M}$ acetosyringone) for 3 days and then transferred to recovery medium (PES medium without acetosyringone) for 7 days. Finally, transgenic thalli were selected in PES medium containing hygromycin 20 $\mathrm{mg} / \mathrm{L}$ for 14 days.

\section{Detection of Lysozyme Gene in Transgenic K. alvarezii}

Genomic DNA was extracted from putative bud of transgenic K. alvarezii using CTAB reagent (Doyle \& Doyle 1987). DNA sample $(1 \mu \mathrm{L})$ was used in a $10 \mu \mathrm{L}$ PCR mixture. The PCR primers for Lys detection were Lys-F and Lys-R; 35S CaMV-F and Lys-R; and Lys-F and NosT-R. PCR was performed with 2 minutes initial denaturation at $94{ }^{\circ} \mathrm{C}$ and then 35 cycles were run at: 30 seconds denaturation at 94 ${ }^{\circ} \mathrm{C}, 30$ seconds annealing at $64^{\circ} \mathrm{C}$ (at $59{ }^{\circ} \mathrm{C}$ for Nos terminator) and 1 minute extension at $72{ }^{\circ} \mathrm{C}$. The amplified PCR products were electrophoresed on a $2 \%$ agarose gel with 1x TAE buffer.

\section{RESULTS AND DISCUSSION}

\section{Construction of Lysozyme Expressing Plasmid}

Construction of binary plasmid was done by ligating chicken Lys gene (460 bp) and pMSH1 (12,986 bp). Result of the ligation was 13,449 bp (Fig.3A Lane 1). Verification of E. coli DH5 $\alpha$ containing pMSH-Lys was performed by digesting pMSH1-Lys with NotI and SpeI restriction enzymes. The restriction products were two fragments in size of 12,986 bp and $460 \mathrm{bp}$ (Fig.3A Lane 2). The 12,986 bp fragment was the size of pMSH1, and 460 bp was Lys gene fragment. E. coli DH5 $\alpha$ carrying pMSH1-Lys was also identified using PCR with primers Lys-F and Lys-R; 35S-F and Lys-R, and Lys-F and Nos-R. The results of PCR analysis using those primers were $460 \mathrm{bp}, 670 \mathrm{bp}$ and $580 \mathrm{bp}$, respectively (Fig. 3B). Based on the results, it was concluded that the binary vector $\mathrm{pMSH} 1-\mathrm{Lys}$ was established.

PCR verification and enzyme restriction performed above also confirmed that transformation of pMSH1-Lys into E. coli DH5 $\alpha$ had been successful. Plasmid pMSH1-Lys contained genes encoding protein resistant to antibiotics. Thus, bacterial colony survived and grew in selective medium containing kanamycin and hygromycin was a pMSH1-Lys transformed E. coli DH5 $\alpha$. The pMSH1-Lys could then be used for transformation into $A$. tumefaciens. 

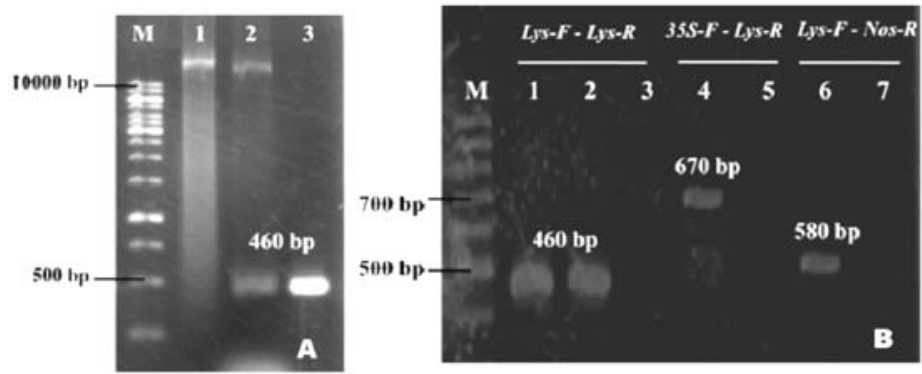

Figure 3. A. Pattern restriction of pMSH1-Lys using NotI and SpeI enzymes. M: 1 kb DNA ladder marker (Fermentas). Lane 1: plasmid of pMSH1-Lys, Lane 2: NotI and SpeI digested pMSH1-Lys and Lane 3: PCR product of Lysozyme gene (Lys). B. Identification of Escherichia coli DH5 $\alpha$ containing Lysozyme gene using PCR with primers Lys-F and Lys-R (Lanes 1, 2 and 3), 35S-F and Lys-R (Lanes 4 and 5) and LysF and Nos-R (Lanes 6 and 7). M: 100 bp DNA ladder marker (Fermentas), Lanes 1, 4 and 6 are DH5 $\alpha$ containing pMSH1-Lys. Lane 2: positive control, pJfKer-Lys. Lanes 3,5 and 7 are the negative control (non-transformant $\mathrm{Dh} 5 \alpha$ )

\section{Transformation of pMSH1-Lys into Agrobacterium tumefaciens}

Transformation of pMSH1-Lys into $A$. tumefaciens was performed by tri-parental mating (Fig.4). Plasmid pMSH1-Lys in E. coli DH5 $\alpha$ (as a donor) was transferred into A. tumefaciens (as a recipient) through the conjugation process by pRK2013 in E. coli DH1 as a helper (Fig. 4A labelled as "konjugasi"=conjugation). E. coli DH5 $\alpha$ containing pMSH1-Lys was resistant to kanamycin and hygromycin, but susceptible to streptomycin. A. tumefaciens was resistant to streptomycin, but susceptible to kanamycin and hygromycin. Thus, bacteria grew on the selective medium was $A$. tumefaciens containing pMSH1-Lys derived from tri-parental mating (Fig.4B). $A$. tumefaciens non-transformant was not grown on the selective medium (Fig. 4C).
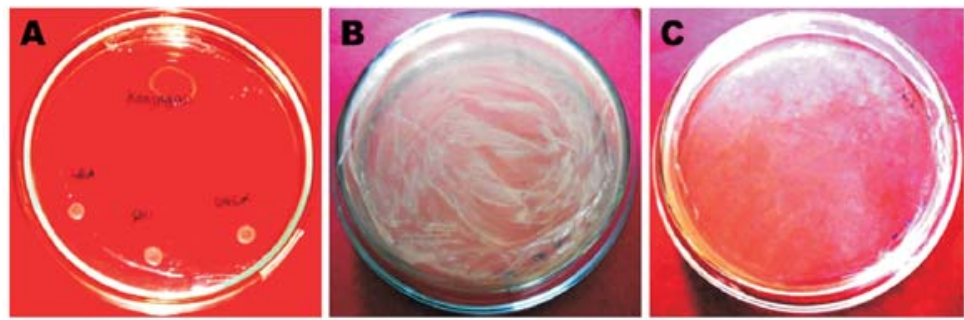

Figure 4. Triparental Mating. A. Results of tri-parental mating grown on LA medium without antibiotics. B. Agrobacterium tumefaciens LBA 4404 transformants on selective medium containing $50 \mathrm{mg} / \mathrm{L}$ hygromycin, $50 \mathrm{mg} / \mathrm{L}$ kanamycin and $50 \mathrm{mg} / \mathrm{L}$ streptomycin. C. A. tumefaciens LBA 4404 non-transformants did not grow on selective medium 
Identification of $A$. tumefaciens transformants was performed by PCR method. As shown in Figure 5, PCR amplification products using Lys-F/Lys-R primer was $460 \mathrm{bp}$ (Lanes 1 and 2), using primers 35S-F/Lys-R was 670 bp (Lanes 4 and 5), and using Lys$\mathrm{F} /$ Nos-R primer was $580 \mathrm{bp}$ (Lanes 7 and 8). This result showed that $A$. tumefaciens contained pMSH1-Lys, and it could then be used for transformation into K. alvareziii.

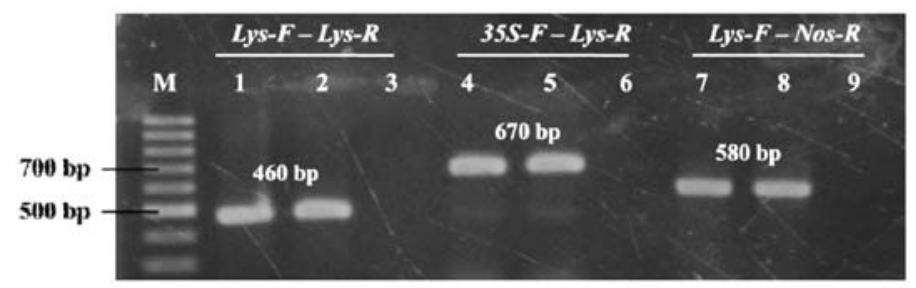

Figure 5. Identification of Agrobacterium tumefaciens containing pMSH1-Lys by PCR method. Lanes 1, 2 and 3: PCR product using primers Lys-F and Lys-R. Lanes 4, 5 and 6: PCR product using primers 35S-F and Lys-R. Lanes 7, 8 and 9: PCR product using primers Lys-F and Nos-R. M: 100 bp DNA ladder marker (Fermentas). Lanes 1, 4 and 7 are $A$. tumefaciens LBA4404 from tri-parental mating. Lanes 2, 5 and 8 are a positive control (DH5 $\alpha$ containing pMSH1-Lys). Lanes 3, 6 and 9 are a negative control (nontransformant $A$. tumefaciens LBA4404)

\section{Transformation of pMSH1-Lys into Kappaphycus alvarezii}

K. alvareaii thalli were adapted on the PES culture medium (liquid and solid), and then were transformed with pMSH1-Lys by $A$. tumefaciens (Fig.6). The result showed that after 30 minutes infection with $A$. tumefaciens at OD600 of 0.5 to 0.8 , the transformed thalli could grow in PES medium containing $100 \mu \mathrm{M}$ acetosyringone (Fig.6). The transformed thalli could grow on selective medium containing $20 \mathrm{mg} / \mathrm{L}$ hygromycin (Fig. 6A-C). Non-transformant thalli was gradually dead on selective medium containing $20 \mathrm{mg} / \mathrm{L}$ hygromycin (Fig. 6D-F). Wild type thalli could grow on PES medium (Fig. 6G-I).

In total, 53 out of 225 transformed thalli $(23.56 \%)$ grew on hygromycin selective medium (Table 1). This number was lower compared to percentage of gene LacZ transformation on Gracilaria changii using particle bombardment methods (80-94\%). The result found in this study was thought to be affected by the difference of transformation method. In the next study, genetic transformation protocols of $K$. alvarez $i$ ii need to be improved for increasing the transformation percentage. There were $3(11.32 \%)$ thalli succeeded to germinate. Efficiency of putative sprouting ratio was determined by the number of putative sprouting thalli grew on hygromycin selective medium. The result showed that the efficiency of putative germination transformed thalli was lower than those of non-transformed ones $(22 \%)$. It might be caused by Agrobacterium infection and antibiotic selective medium. This finding was in accordance with Suma et al. (2008) that the addition of antibiotics in selective medium 
can cause thallus growth and development decrease. Optimum infection duration and different treatment methods on selective medium in future research is expected to result in higher germination efficiency. Transformation percentage in this study was $23.56 \%$ (Table 1$)$.
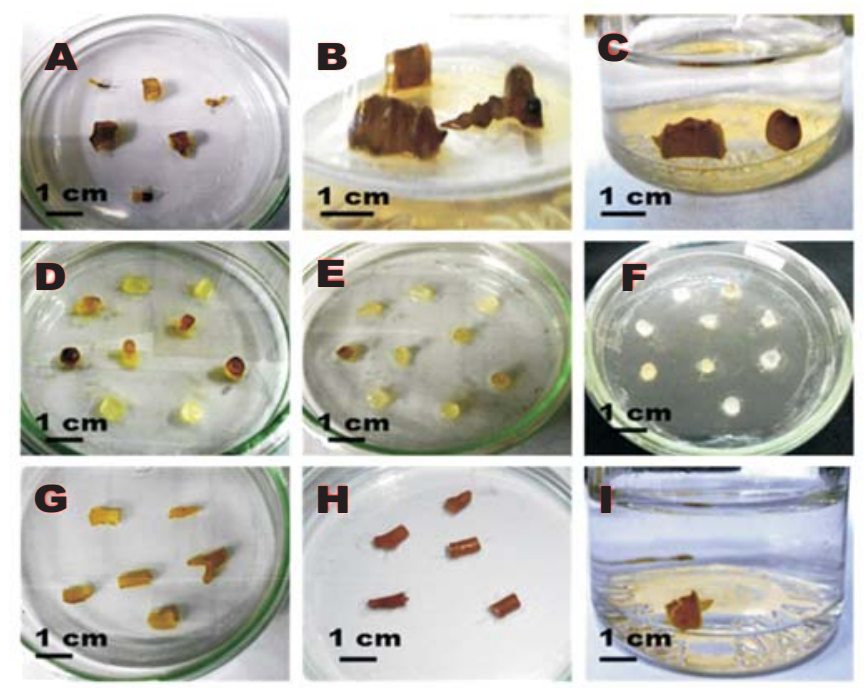

Figure 6. Development of Agrobacterium tumefaciens transformed Kappaphycus alvarezii thalli at 4 (A), 8 (B) and 12 (C) weeks culture in selective medium containing $20 \mathrm{mg} / \mathrm{L}$ hygromycin. Non-transformant thalli at 4 (D), 8 (E) and 12 (F) weeks culture in selective medium containing $20 \mathrm{mg} / \mathrm{L}$ hygromycin. Non-transformant thalli in the medium without hygromycin at $4(\mathrm{G}), 8(\mathrm{H})$ and 12 (I) weeks culture. In D-F, green color indicates survived thalli, while the white color indicates dead thalli

Table 1. Transformation percentage and putative bud of Kappaphycus alvarezii containing lysozyme gene

\begin{tabular}{lcccccc}
\hline Treatment & $\begin{array}{c}\text { Number } \\
\text { of } \\
\text { thalli }\end{array}$ & $\begin{array}{c}\text { Number of } \\
\text { hygromycin } \\
\text { resistant } \\
\text { thalli }\end{array}$ & $\begin{array}{c}\text { Percentage of } \\
\text { transformationa) }\end{array}$ & $\begin{array}{c}\text { Number } \\
\text { of } \\
\text { putative } \\
\text { bud }\end{array}$ & $\begin{array}{c}\text { Number } \\
\text { of } \\
\text { positive } \\
\text { by PCR }\end{array}$ & $\begin{array}{c}\text { Efficiency } \\
\text { of } \\
\text { putative } \\
\text { bud b) }\end{array}$ \\
\hline Transformation & 225 & 53 & $23.56 \%$ & 6 & 3 & $11.32 \%$ \\
Control -1) & 50 & 0 & 0 & 0 & 0 & 0 \\
Control +2) & 50 & - & 0 & 11 & 0 & $22 \%$ \\
\hline
\end{tabular}

Notes:: The percentage of the number of hygromycin-resistant thalli versus the total number of thalli transformed

b) The percentage of the number of thalli that sprouts putative versus number of hygromycinresistant thalli

1) Non-transgenic thalli in hygromycin selective medium

2) Non-transgenic thalli in non-hygromycin medium 
Presence of Lys gene in K. alvarerzii was confirmed by PCR method using three primers set. As shown in Figure 7, transgenic thalli (Lanes 1, 4 and 7) possessed PCR amplicon in the same size with the positive control of pMSH1-Lys plasmid (Lanes 2, 5 and 8), while the non-transgenic thalli showed no amplicon. This indicated that the putative bud derived from $A$. tumefaciens transformation was transgenic carrying Lys gene.

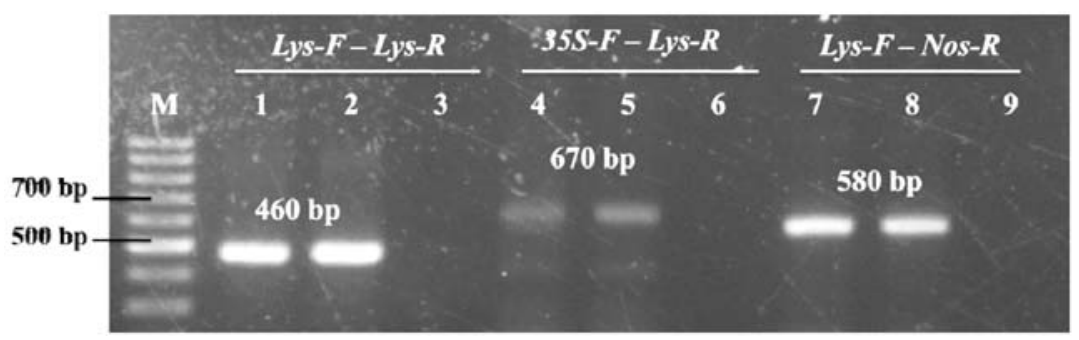

Figure 7. Lysozyme gene detection in Agrobacterium tumefaciens transformed Kappaphycus alvarezii thalli by PCR method. Lanes 1, 2 and 3: PCR products using Lys-F and Lys-R primers; Lanes 4, 5 and 6 using 35S-F and Lys-R primers; Lanes 7, 8 and 9 using primers Lys-F and Nos-R primers. M: 100 bp DNA ladder marker (Fermentas). Lanes 1, 4 and 7 are transgenic thalli; Lanes 2, 5 and 8 are positive control (plasmid of pMSH1-Lys); Lanes 3, 6 and 9 are negative control (wild type of seaweed).

This study is the first transgenic $K$. alvarezii production using $A$. tumefaciens infection method and Lys gene as the transgene. Analysis of Lys gene activity in transgenic $K$. alvarezii againts ice-ice bacterial agent is in progress. This transgenic $K$. alvarezii can also be useful for studying the mechanisms of seaweed defense against bacterial infection. In addition, transgenic seaweed resistance to ice-ice disease can be useful to ensure seaweed production in the season when ice-ice disease frequently infects. Transformation method developed in this study is beneficial to produce other transgenic seaweed expressing protein that regulates important traits in aquaculture. Examples of interesting genes that can be used to generate transgenic seaweed are cooper/zinc superoxide dismutase (CuZn-SOD) and omega-3 highly unsaturated fatty acids (n-3 HUFA) metabolic enzymes. Those enzymes had been used in plant transgenic production. CuZn-SOD had successfully been transformed in Nicotiana tabacum to increase its resistant to environmental stress (Hannum 2012). Transgenic Arabidopsis expressing n-3 HUFA metabolic enzymes had also been generated (Robert et al.2005).

\section{CONCLUSIONS}

Construction of the binary plasmid pMSH1-Lys was established with size of 13,449 bp. Agrobacterium tumefaciens mediated transformation of lysozyme gene could produce transgenic Kappaphycus alvareziii. The efficiency of putative bud was $11.32 \%$, while percentages of positive transformants were approximately $23.56 \%$. 


\section{ACKNOWLEDGEMENTS}

This research was supported by the collaboration between Research Institute for Coastal Aquaculture, Maros and Research Center for Bioresources and Biotechnology, Bogor Agricultural University. Our thanks to Department of Aquaculture, Faculty of Fisheries and Marine Science, Bogor Agricultural University for technical support.

\section{REFERENCES}

Amiluddin NM. 2007. A study of growth and carrageenan content of Seaweed Kappaphycusalvarezii that are affected by Ice-ice disease in Pari Island, Thousand Islands. PhD thesis. Bogor (ID): Institut Pertanian Bogor.

Aris M. 2011. Identification, pathogenicity of bacteria and the use of gene 16S rRNA for ice-ice detection onseaweed aquaculture (Kappaphycus alvarezii). PhD thesis. Bogor (ID): Institut Pertanian Bogor.

Bixler H.1996. Recent developments in manufacturing and marketing carrageenan. Hydrobiologia 326/327: $35-$ 57.

Burge EJ, Madigan DJ, Burnett LE, Burnett KG. 2007. Lysozyme gene expression by hemocytes of Pacific white shrimp Litopenaeus vannamei, after injection with Vibrio. Fish Shelfish Immun 22: 327-39.

Cheney D, Metz B, Stiller J. 2001. Agrobacterium-mediated genetic transformation in the macroscopic marine red algae Porphyra yezoensis. J.Phycol 37:11-2.

Doyle JJ, Doyle JL. 1987. A rapid DNA isolation procedure for small quantities of fresh leaf tissue. Phytochem. Bull. 19:11-5.

Fletcher GL, Hobbs RS, Evans RP, Shears MA, Hahn AL, Hew CL. 2011. Lysozyme transgenic Atlantic salmon (Salmo salar L.). Aquaculture Res 42: 427-40.

Hannum S. 2012. Isolation, cloning, and expression analysis of gene coding copper/zinc superoxide dismutase (CuZn-SOD) from Melastoma malabathricum L. PhD thesis. Bogor (ID): Institut Pertanian Bogor.

Hiei Y, Komari T, Kobu T. 1997. Transformation of rice mediated by Agrobacterium tumefaciens. Plant Mol. Biol 35: 205-18.

Huddy SM, Meyers AE, Coyne VE. 2012. Transformation of LacZ using different promoters in the commercially important red alga, Gracilaria gracilis. Afr. J. Biotechnol 11(8): 1879-85.

Largo DB. 2002. Recent developments in seaweed diseases. In: The National Seaweed Planning Workshop. Proceeding: 2001 Aug 2-3; Tigbauan. Iloilo (PH): SEAF DEC. pp 35-42.

Li H, Parisi MG, Toubiana M, Cammarata M, Roch P. 2008. Lysozyme gene expression and hematocyte behaviour in the Mediterranean mussel, Mytilus galloprovincialis, after injection of various bacteria or temperature stresses. Fish and Shellfish Immunol 25(1-2): 143-52.

Liberty, Herman M, Wattimena GA. 2008. Construction of binary plasmids carrying Cry1Ab gene and binary plasmid transformation by triparental mating method. Zuriat 19(2): 130-9.

Loeidin IHS. 1994. Genetic transformation in plants: techniques and important aspects. HAYATI 1(2): 66-7.

Nasution MH. 2005. Pathogenic of Bacteria Isolates on Seaweed Kappaphycus alvarezii in Pari Island, Thousand Islands. Jakarta (ID): Faculty of Biology, National University Jakarta.

Robert SS, Singh SP, Zhou XR, Petrie JR, Blackburn SI, Mansour PM, Nichols PD, Liu Q, Green AG. 2005. Metabolic engineering of Arabidopsis to produce nutritionally important DHA in seed oil. Functional Plant Biology 32: 473-9. 
Suharsono U, Fujisawa Y, Kawasaki T, Iwasaki Y, Satoh H, Shimamoto K. 2002. The hetero trimeric G protein $\alpha$ subunit acts upstream of the small GTPaseRac in disease resistance of rice. Proc. Natl. Acad. Sci 99: 13307-12.

Suma B, Keshavachandran K, Nybe EV. 2008. Agrobacterium tumefaciens mediated transformation and regeneration of ginger (Zingiber officinale Rosc.). J. Trop. Agri 46 (1-2): 38-44.

Takahashi M, Uji T, Saga N, Mikami K. 2010. Isolation and regeneration of transiently transformed protoplasts from gametophytic blades of the marine red alga Porphyra yezoensis. Electronic J Biotechnol 13(2): 1-4.

Yazawa R, Hirono I, Aoki T. 2005.Characterization of promoter activities of four different Japanese flounder promoters in transgenic zebrafish. Mar. Biotechnol 7: 625-33.

Yazawa R, Hirono I, Aoki T. 2006. Transgenic zebrafish expressing chicken Lysozyme show resistance against bacterial diseases. Transgenic Res 15: 385-91.

Yu G, Guan H, Ioanoviciu AS, Sikkander SA, Thanawiroon C, Tobacman JK, Toida T Linhardt RJ. 2002. Structural studies on k-carrageenan derived oligosaccharides. Carbohydrate Res 337:433-40.

Yulianto K, Mira S. 2009. A study of Kappaphycus alvarezii (doty) culture using the vertical line method and the symtomps of "ice-ice" disease in Pari Island waters. OLDI 35(3): 323-32. 